\title{
FAMILY THERAPY OF THE MODERATE TYPE OF PARENTAL ALIENATION SYNDROME
}

\author{
RICHARD A. GARDNER \\ Department of Child Psychiatry, College of Physicians and Surgeons, \\ Columbia University, New York, New York, USA \\ from The American Journal of Family Therapy. 27:195-212, 1999 \\ Each of the three types of parental alienation syndrome (PAS) \\ warrants a different therapeutic approach. Because PAS is a \\ family problem, family therapy is usually warranted-separation, \\ divorce, and even litigation notwithstanding Furthermore, \\ formidable modifications of traditional family therapy approaches \\ are warranted if there is to be any chance of success in the \\ treatment of PAS families. Especially important is the full support \\ of the court for the therapist's stringent and authoritarian methods \\ necessary for the treatment of these families. Without such support, \\ the therapist is not likely to be successful. Described here are the \\ special family therapeutic techniques warranted in the treatment of \\ families in which the PAS is of the moderate type.
}

Parental alienation syndrome (PAS; Gardner, 1985, 1986, 1987a, 1987b, 1989, 1992a, 1998) is a psychiatric disturbance that arises in the context of litigated child custody disputes, especially when the dispute is prolonged and acrimonious. There are three types of parental alienation syndrome, the differential diagnosis of which is crucial if one is to properly treat the disorder. In Table 1 the primary manifestations of each of the three types are delineated. In this article I focus on the treatment of the moderate type. Because PAS is a family problem, a family therapy approach is warranted - separation, divorce, and litigation notwithstanding.

\section{BASIC STRUCTURE OF THE THERAPEUTIC PROGRAM}

When working with PAS families, it is important that only one therapist be used. This is not a situation in which the mother should have her therapist, the father his therapist, and the children their own. Such a program, although seemingly respectful of each party's individual needs, is not likely to work for PAS families. Such fractionalization reduces communication, is likely to set up antagonistic subsystems within the family, and will probably intensify and promulgate the pathological interactions that contribute to PAS. Therapists who treat PAS children individually are likely to be "led down the garden path" and seduced into believing that their patients have indeed been subjected to the humiliations that PAS children are so skilled at describing. The same principle holds for therapists who work individually with the programming parent. The therapist needs input from both parents. The therapist needs input from the victimized parent to learn directly how inappropriate and ludicrous the children's complaints are, and the therapist 
needs direct experience with the alienator to observe that parent's manipulations directly. It is only by treating all family members, individually and in varying combinations, that one can get a full appreciation of a PAS family psychodynamics.

TABLE 1

Differential Diagnosis of the Three Types of Parental Alienation Syndrome

\begin{tabular}{|c|c|c|c|}
\hline $\begin{array}{l}\text { Primary Symptomatic } \\
\text { Manifestation }\end{array}$ & Mild & Moderate & Severe \\
\hline Campaign of denigration & Minimal & Moderate & Formidable \\
\hline $\begin{array}{l}\text { Weak frivolous, or absurd } \\
\text { rationalizations for the } \\
\text { deprecation }\end{array}$ & Minimal & Moderate & $\begin{array}{l}\text { Multiple absurd } \\
\text { rationalizations }\end{array}$ \\
\hline Lack of ambivalence & $\begin{array}{c}\text { Normal } \\
\text { ambivalence }\end{array}$ & No ambivalence & No ambivalence \\
\hline $\begin{array}{l}\text { Independent-thinker } \\
\text { phenomenon }\end{array}$ & Usually absent & Present & Present \\
\hline $\begin{array}{l}\text { Reflexive support of the } \\
\text { alienating parent in the } \\
\text { parental conflict }\end{array}$ & Minimal & Present & Present \\
\hline Absence of guilt & Normal guilt & $\begin{array}{l}\text { Minimal to no } \\
\text { guilt }\end{array}$ & No guilt \\
\hline Borrowed scenarios & Minimal & Present & Present \\
\hline $\begin{array}{l}\text { Spread of the animosity to } \\
\text { the extended family of } \\
\text { the hated parent }\end{array}$ & Minimal & Present & $\begin{array}{l}\text { Formidable, often } \\
\text { fanatic }\end{array}$ \\
\hline $\begin{array}{l}\text { Transitional difficulties at } \\
\text { the time of visitation }\end{array}$ & Usually absent & Moderate & $\begin{array}{l}\text { Formidable, or } \\
\text { visit not possible }\end{array}$ \\
\hline Behavior during visitation & Good & $\begin{array}{l}\text { Intermittently } \\
\text { antagonistic and } \\
\text { provocative }\end{array}$ & $\begin{array}{l}\text { No visit, or } \\
\text { destructive and } \\
\text { continually } \\
\text { provocative } \\
\text { behavior }\end{array}$ \\
\hline Bonding with the alienator & Strong, healthy & $\begin{array}{l}\text { Strong, mildly } \\
\text { to moderately } \\
\text { pathological }\end{array}$ & $\begin{array}{l}\text { Severely } \\
\text { pathological, } \\
\text { often paranoid } \\
\text { bonding }\end{array}$ \\
\hline $\begin{array}{l}\text { Bonding with the alienated } \\
\text { parent }\end{array}$ & $\begin{array}{l}\text { Strong, healthy, } \\
\text { or minimally } \\
\text { pathological }\end{array}$ & $\begin{array}{l}\text { Strong, healthy, } \\
\text { or minimally } \\
\text { pathological }\end{array}$ & $\begin{array}{l}\text { Strong, healthy, } \\
\text { or minimally } \\
\text { pathological }\end{array}$ \\
\hline
\end{tabular}


It also is important that the treatment be court ordered and the therapist have direct input to the judge. This can often be facilitated by the use of a guardian ad litem or a child advocate who has the opportunity for direct communication with the court. The alienating parent must be fully aware that any obstruction to the treatment or interference with the visitation process will be immediately reported to the judge, either by the therapist directly or through the guardian ad litem. The court must be willing to impose sanctions for recalcitrants-for example, fines, transfer of custody, or even jail. If the court is unwilling to impose such sanctions, then the therapy is likely to prove futile.

Therapists who work with PAS families must be comfortable with authoritarian approaches. There is no place in such treatment of patiently waiting for patients to gain insight. This is especially true when the therapist is dealing with the alienating parent. The therapist who cannot switch roles and be comfortable with a stringent, authoritarian approach should not be treating such families. Furthermore, the therapist must be comfortable with a treatment program in which there is a modification of traditional confidentiality. Specifically the therapist must have free access to reveal, at his or her discretion, any and all information disclosed in the treatment to specific outside parties, such as attorneys on both sides, the guardian ad litem, and the court. Without such freedom, the therapy is likely to prove futile.

\section{THE COURT SANCTIONS PROGRAM}

Before embarking on the treatment, the therapist must have a clear idea regarding exactly what the nature of the court's support will be. All of the possible sanctions should be spelled out clearly in a court order. As the court's impartial therapist, direct communication with the judge is possible in order to clarify this issue. Such therapists must know exactly what threats they can use to lend support to their suggestions, instructions, and even manipulations, I have no hesitation using the word threats. Life is filled with threats. If one doesn't pay one's household bills, services are discontinued. If one repeatedly does not show up for work, one ultimately gets fired. Without threats there would be no organized civilized society. And traditional therapy has its threats; for example, "If you don't pay your bills, I'm going to seriously consider discontinuing treatment," and "If you don't cooperate with regard to taking the medication I'm prescribing, I don't think I can be of help to you." It is in the treatment of PAS families that threats are crucial. Empty threats are not only a waste of time but also compromise the treatment. Threats that have little if any possibility of implementation provide the therapist with a reputation of being weak and impotent and significantly compromise the likelihood that the treatment will be effective. In order for the threats to have clout, the therapist must be court ordered. Otherwise, the therapist's threats are going to be meaningless.

Generally, the threats necessary to use in the treatment of PAS families lie on a hierarchy, and the therapist does well to pose them in order from mildest to most severe. A mild threat might simply be that the therapist will report the parent's lack of cooperation to the court. A higher level threat might involve a court-ordered reduction in the payments the alienated parent is required to provide to the alienator. Of course, there are limitations to this threat in that one cannot leave the programming parent destitute or incur such privations that the children will not be cared for properly. Obviously, this threat will be less efficacious for the wealthy than for the poor. Also, this threat is not viable when the alienated parent is not giving any money at all to 
the alienator. Sometimes a fine for each failure to produce the children will work; sometimes a more ongoing type of financial withholding may be necessary to help the alienator cooperate. The threat of permanent transfer of the children to the primary custody of the victimized parent (with the alienator then having visitation) can sometimes be invoked.

The highest level threat is jail. In recent years, fathers have commonly been jailed for failure to fulfill financial commitments, but I have no personal experience with mothers being jailed for failure to fulfill their commitment to enforce the visitation of the children with their fathers. Although I have repeatedly recommended such a ruling or rulings to courts, I have thus far not been successful in convincing judges that this is the only "treatment" that is likely to work. One could start with house arrest, in which the alienator would be put to jail if discovered out of the home during a prescribed period, such as the time frame of the court-ordered weekend visitation. If this does not prove efficacious, then the next step would be the more traditional house arrest, in which there is random telephone monitoring by the police and an electronic ankle band that communicates with the local police station. The next step is more formal incarceration in the local jail. Usually short periods suffice to help the alienating parent "remember" to produce the children at the assigned times.

\section{THE ALIENATING PARENT}

Alienators in the moderate category of PAS will often find their own individual therapists with whom they develop a mutual admiration society in which the therapist (consciously or unconsciously) becomes the programmer's champion in the conflict. Parents in this category have a way of selecting therapists who will support their antagonism toward the targeted parent. My experience has been that this is much more often the case for female alienators than male alienators. Most often, such programming mothers choose a female therapist-especially a woman who is generally antagonistic toward men Typically, the mother's therapist has little, if any, contact with the father and so deprives herself of the opportunity to hear his view of the situation. When such therapists do meet with him, they typically will be hostile and unsympathetic. Accordingly, the mother and the therapist often develop a folie-à-deux relationship. However, when one, considers the fact that the programming parent already has a folie-à-deux relationship with the child, the addition of such a therapist justifies the term folie-à-trois for the arrangement. Although the court may not wish to prohibit the mother from seeing this therapist, it does well to prohibit the children from being "treated" by her (as mentioned, the therapist is rarely a man). Even if the court were to order the mother's therapist to stop treating her, it is likely that she will find another therapist who will naively support her in the programming process. Accordingly, I do not generally recommend that the court order a cessation of the mother's treatment with the therapist with whom she is pathologically involved. The court should order the mother to see the court's therapist, even though her maneuvers to obstruct the court-ordered therapy may be significantly supported by her own therapist.

Typically, PAS indoctrinators in the moderate category will either refuse meaningful involvement in the special treatment program described here or, if they profess such interest, will ultimately be uncooperative, obstructionistic, and do everything possible to sabotage the therapy. They may profess interest and cooperation, but their behavior attests to just the 
opposite. PAS-inducing parents "can create a facade of wanting peace and cooperation, while covertly continuing the campaign of aggression and sabotage."

The therapist should do everything reasonably possible to find some healthy "insider" on the alienator's side of the family. Sometimes the alienator's mother, father, or sibling can serve in this capacity. One is seeking a person who is aware that the alienator is "going too far" with regard to the animosity that she or he harbors toward the spouse and is fostering the children's alienation. If a good relationship existed between the victim's parents and the alienator's parents prior to the separation, the therapist might prevail on the victim's parents to speak with the alienator's parents. Sometimes family meetings in which both parents and all four grandparents are present can be useful. The alienator's mother can be a very powerful therapeutic ally if the therapist is able to enlist her services. I cannot emphasize strongly enough the importance of the therapist's attempting to find such an ally on the alienator's side of the family. Such individuals can sometimes bring programmers to their senses and effectively prevail on them to "loosen up" and appreciate how detrimental their maneuvers are to the children. Many parties who are appreciative of the programming parent's injudicious behavior take the position of "not wanting to get involved." In some cases, these individuals fear that if they do not support the programmer's position they, too, will become the targets of the same rage that is directed toward the victimized parent. The therapist does well to attempt to have access to such people and to impress on them that their neutrality may be a terrible disservice to the children. I have no problem generating guilt in such individuals if it will serve the purpose of facilitating their involvement in the therapeutic process.

Most of the alienators in the moderate category of PAS are not receptive to insight therapy in which they delve into the reasons for their exaggerated animosity. There are, however, some PAS indoctrinators in this category who may indeed involve themselves meaningfully in the therapeutic process. At the most superficial level, one tries to get them to appreciate the importance of the other parent's role in the children's upbringing and to recognize that their PAS-inducing manipulations, although causing grief to the victimized parent, are also contributing to the children's psychopathology. Many PAS inducers have been so blinded by their rage that they do not appreciate this obvious effect of their campaign of denigration and exclusionary techniques.

Sometimes the alienator's rage stems from jealousy that the vilified parent has a new involvement and the alienator does not. Such jealousy is a contributing factor to the program designed to exact vengeance on the former spouse by depriving the hated spouse of the children, his or her most treasured possessions. Another factor that often contributes to the PAS campaign of animosity is the alienator's desire to maintain a relationship with the former spouse. Inducing PAS in a child cannot be accomplished in one single maneuver. It requires ongoing monitoring, adjustments, and "the injection of booster shots." The tumult so engendered guarantees ongoing involvement, accusation and counteraccusation, and attack and counterattack. Most people, when confronted with a choice between total abandonment and hostile involvement, would choose the acrimonious relationship. The PAS inducer demonstrates this point well. To the extent that one can help such a parent pick up the pieces of her or his life and form new involvements and interests, one is likely to reduce this element in the rage. The most therapeutic experience such a 
parent can have is meeting a new companion with whom she or he becomes deeply involved and forms a strong relationship.

Economic factors may contribute to a PAS mother's anger. Divorced women generally suffer more financial privation than their husbands. This is a common contributing factor to the rage that fuels PAS indoctrinations. If the therapist has compelling reasons to believe that the mother has been "short-changed" in the settlement, then professional input (from accountants and knowledgeable lawyers) may be warranted. In such cases the therapist does well to inform the court (preferably by letter, with copies to the parents and their attorneys) that he or she has good reason to believe that the property and financial settlement has not been fair, that the mother's unnecessary privations are contributing to the anger that is perpetuating the PAS, and that a more egalitarian settlement would prove therapeutic for ail concerned. Therapists must appreciate that they are not accountants or financial lawyers and that what may appear to the mother to be an unfair settlement may, in fact, not be. Accordingly, the therapist should not come to any final conclusions on this matter but should leave this to the proper experts.

Maternal overprotectiveness is commonly a factor in producing PAS in the children. Such mothers view the world as a dangerous place, and the father may be viewed as a potential source of danger to the children. Therapeutic alleviation of the overprotectiveness, then, may prove useful in reducing such a mother's propensity to engender PAS in her children. If the mother has sexual inhibition problems that result in her projecting her sexual impulses in sum a way that she promulgates a false sex abuse charge, this problem must be addressed as well (Gardner, 1996). All sources of anger, both related to and unrelated to the spouse, should be investigated - especially if they result in anger being channeled into the vengeance and rage directed toward the victimized parent.

I have been involved in many cases in which mothers in the moderate category suddenly decide that they want to move to another state. They suddenly become "homesick," after many years of comfortable adjustment in the locale where the children were raised. Some suddenly decide that they want to remove themselves (and the children, of course) from the scene of the custody conflict (including the whole state) and "start all over" or "find themselves" at some remote place. A few claim better job opportunities exist in another state. Some claim a new romantic involvement with a man who resides and works at this remote location. The therapist should examine carefully the reasons for such sudden decisions to relocate. Of course, there are women who do indeed meet a new person, and involvement with that individual may be possible only if they relocate. And there are indeed women who do have better job opportunities elsewhere. However, when a PAS is present, the therapist should conduct a detailed inquiry into the request and be very suspicious regarding the justification for the move. When it is obvious that the decision is yet another exclusionary maneuver in the context of a PAS, then the court should be advised to inform the mother that she is free to leave the state at any time she wishes (as is done for any adult); however, she should recognize (as if she does not appreciate it already) that the children will remain in their original location with the despised spouse as the primary caretaker. In recent years, courts have become increasingly receptive to such requests by mothers (far less so when the request comes from the father) and this, I believe, is an unfortunate trend. Elsewhere (Gardner, 1998) I have commented on this phenomenon. 


\section{THE CHILDREN}

The court's therapist must have a thick skin and be able to tolerate the shrieks and claims of impending maltreatment that PAS children often profess. Doing what children profess they want is not always the same as doing what is best for them. Therapists who believe that they must "respect" their child patients and accede to their wishes will be doing PAS children a terrible disservice. These same therapists would not "respect" a child's wish to refuse a polio shot, yet they will respect the child's wish not to visit with a parent who shows no significant evidence for abuse, maltreatment, or neglect. (Again, I take the opportunity here to repeat what I have repeatedly emphasized previously [Gardner, 1992a, 1998], that when bona fide abuse is present, the PAS diagnosis is not applicable.) The therapist does well to recall that prior to the separation the children were likely to have had a good, strong relationship with the targeted parent and that strong psychological ties must still be present. Accordingly, the therapist should view PAS children's professed animosity as superficial and designed to ingratiate themselves with the alienator. To take the allegations of maltreatment seriously, is a terrible disservice to PAS children. It may contribute to an entrenchment of the PAS and may result in years of, if not lifelong, alienation.

Similarly, when a fabricated (as opposed to bona fide) sex abuse allegation has been introduced, if the therapist is convinced that it is false (especially after thorough evaluation [Gardner, 1995]), then he or she does well not to allow the children to dwell on these allegations. Typically over time such false allegations become elaborated on, and new allegations arise when the earlier ones do not result in the targeted parent being totally removed from access to the children. Accordingly, it is antitherapeutic to listen to these. Rather, it is therapeutic to say, "That didn't happen! So let's go on and talk about real things, like your next visit with your father." A false sex abuse allegation may become an intrinsic part of the PAS and may become a formidable additional dimension. However, it is beyond the purposes of this article to discuss in detail the incorporation of sex abuse allegations into the PAS. I have discussed this important dimension, however, elsewhere (Gardner, 1987a, 1991, 1992a, 1992b, 1993a, 1993c, 1995, 1996, 1998).

Therapists must appreciate that PAS children need them to serve as an excuse for visiting with the victimized parent. When "forced" by the therapist to visit with the alienated parent, PAS children can say to the programmer that the therapist is mean, cruel, and so on, and that they really do not want to see the despised parent, but the therapist "makes them." And the judge should appreciate that he or she, too, can serve this function for the children. With a court order, they can say to the alienator, "I really hate my father (mother), but that stupid judge is making me see him (her)." I cannot emphasize this point strongly enough. Not appreciating this principle is one of the most common errors made by therapists involved in the treatment of PAS children. Specifically, they fail to appreciate that the children actually want to be forced to visit so that they have an excuse to do so, and such an excuse necessarily involves complaints about the therapist's coercions and cruel manipulations. PAS children are far more likely to make such excuses when a bona fide threat of sanctions has been ordered by the court and the children have been apprised, to a degree commensurate with their age and level of understanding, that there will be court-ordered painful consequences to the alienators if they do not visit. Under such circumstances, the programming parent might then start to pressure the children to visit in order to protect her- or himself from the consequences of being in contempt of court. Whereas 
previously the indoctrinators' professions to the children that they wanted them to visit the victimized parent were feigned and hypocritical, when meaningful sanctions have been ordered by the court, the indoctrinators may now really "mean business" when they urge the children to visit, because they appreciate that the court is serious and that they will actually suffer serious consequences (including house arrest and even incarceration) if the children do not visit. Accordingly, it is not only the children who are likely to respond to threats of court sanctions but also the alienator.

The following interchange took Place in the context of a discussion I had with Sally, a 6-year-old PAS child who refused to visit with her father for a whole weekend (as ordered by the court) but agreed to see him for ,hour or two. This decision, of course, represented a compromise between her two parents' requests of her.

Gardner: What would you do if the judge said that if you don't see your father for a full weekend, he'll stop your mother's money for that week?

Sally: I wouldn't see him. I'd get a job and give her all the money I have.

Gardner: Suppose he said that if you don't see him, he'll stop your mother's money forever. She'd have no money. What would you do?

Sally: All of us (Sally and her two brothers) would get jobs.

Gardner: Suppose the judge said that if you don't see your father for a full weekend, he'll put your mother in jail for that weekend?

Sally: My mother said she'd go to jail for me if I was that uncomfortable with him and didn't want to go.

Gardner: Suppose the judge said, "I'll keep her in jail unless you go and I'll keep her in jail until you go."

Sally: I guess I'd go!

This is a classical PAS interchange. The child is only "uncomfortable" and has only a vague sense that does not want to go visit with her father. Without any specifics, she is willing to suffer for herself and her mother these Draconian restrictions. However, at the bottom line, when told that her mother would remain in jail as long as she refused to visit with her father, Sally readily submitted. Often PAS children need this excuse. They need to be able to say to their programmers that they hate the victimized parent and are agreeing to visit only to protect the indoctrinator from court sanctions. The children need to be aware of such court threats of sanctions and even knowledge of sanctions that have actually been implemented. Often, the threats are not enough, and an implemented sanction can get the alienator and children to appreciate the fact that the court means business. If the court is not willing to order such sanctions, and if the court is not willing to impose them if court warnings are not complied with, 
then the therapist's position is considerably weakened, and the total treatment program is likely to prove futile.

To justify visiting the vilified parent, PAS children may embrace various excuses. These rationalizations, they hope, will convince their programmers to approve their visiting the estranged parent. One PAS child said to me "The only reason I see him is for his money. When I go there he gives me money." Another child said, "My father said he won't give us any money if I don't go and see him. So that's why I'm going. If I stop going there, we'll all starve to death."

The therapist must also appreciate that older children may promulgate the programming down to younger ones. My experience has been that the oldest children are the first to exhibit PAS manifestations and then the disorder progressively travels down to the younger ones. Accordingly, at any time one may see varying degrees of alienation among the children, even to the point where the eldest may be diagnosed as severe, a middle child as moderate, and the youngest child as mild. Waldron and Joanis (1996) also described this phenomenon. The older children are especially likely to program the younger children during visits with the targeted parent. The programmer thereby can rely on her or his, accomplice to "work over"' the younger ones when in the "enemy" camp. These older children are justifiably referred to as "ringleaders." They may wind the other children up to be disrespectful, disruptive, obstructionistic, and to engage in a wide variety of other activities that serve to act out the alienator's anger.

Because of the separation, the programming parent has less access to the targeted parent. An effective way to enjoy release of such anger is to program the children to act out the alienator's rage in the home of the alienated parent. The older siblings may not only take on the role of surrogate programmer but also may assume other parenting roles. This comes about because the vilified parent is often viewed as an incompetent, and so someone has to fill the vacuum. Or, the targeted parent may be viewed as dangerous, and so someone has to protect the younger sibling(s). In the course of such "parenting" the older child may repeat verbatim the programmer's PAS indoctrinations; for example, "This isn't a safe place," "You've got to keep an eye on him [the alienated father]," "There he goes again, giving us less food than he gives his girlfriend." Some older PAS children may even mastermind "inside jobs" in the denigrated parent's house; for example, stealing money from the alienated parent and encouraging the destruction of property. The word sabotage is an appropriate term for such maneuvers.

A divide-and-conquer approach is usually warranted in situations in which older children are programming younger siblings to sabotage the visit, provoke the targeted parent, and cause him or her grief in other ways. This is best accomplished by requiring the children to visit separately-or at least separate from the older sibling programmer-until they all (including, possibly the alienating parent) have had the actual experience that the terrible consequences of being alone with the targeted parent were not realized. For example, an older sister may be programming her two younger brothers into believing that their father is dangerous and noxious. When they visit with the father and relax their guard, she may quickly remind her younger brothers about the indignities they are likely to suffer in his home. Structuring the visitations so that the sister visits the father separately from her brothers (at least for a time) is the most effective way of dealing with this kind of problem. We see here a good example of an important aspect of the therapy of PAS families, namely, that less is gained through the attempt to get 
family members to gain insight, and much more is accomplished by structuring situations and providing individuals with actual experiences.

The times when the children are transferred from the home of the alienating parent to that of the victimized parent may be especially difficult for PAS children. It is then (when both parents and the children are together) that the loyalty conflicts become most intense and the PAS symptoms most severe. In that setting - with the alienator directly observing the children - they are most likely to resist going with the victimized parent and will predictably gain the programmer's support (overt or covert) for their resistance. Alternative transitional arrangements must therefore be devised-arrangements that do not place the children in a situation in which they are with the mother and father at the same time.

A good transition place in the therapist's office. The programming parent brings the children, spends some time with them and the therapist, and then goes home, leaving the children alone with the therapist. It is important that the alienator leave the therapist's office and not wait (even in the waiting room) for the targeted parent to appear. To allow the PAS-inducing parent to remain in the vicinity will predictably sabotage this transitional arrangement and, ultimately, the whole therapeutic program. The therapist then spends time with the children alone. Subsequently the deprecated parent arrives, spend time with the children and the therapist, and then takes them to his or her home. Another option for transfer is to use a truly impartial intermediary, with whom the children have a good relationship, who picks the children up at the alienator's home and brings them to the targeted parent's home. A guardian ad litem, or a neutral third party (which can be hard to find), can serve in this role.

In some families, the children do best with a gradual expansion of the relatively restricted visitation that the court may have previously ordered for the reviled parent. In many cases, the court recognizes the limitations of the earlier stringent visitation program and has made its wishes known to all parties that an expansion is desired. Ideally, the therapist should have the freedom to make the decisions regarding just how much expansion should take place and at what rate. It is impractical (and obviously very expensive and time consuming) to go back to court every time a modification of a visitation schedule is to be effected. With rare exception, in the course of such expansion PAS-inducing parents will complain that the therapist is going too rapidly and not giving the children enough time to adjust. When empirically monitoring such visitations, therapists must rely on their own observations of the children after visitations and recognize that the reports being given by the parties about exactly what happened during the course of the visits may not be fully accurate. It is a serious error for the therapist to allow himor herself to be controlled by PAS inducers into slowing down and even preventing a reasonable expansion of visitation. One PAS-inducing mother viewed these empirical expansions as "experiments" on her children and stated that "I won't subject my child to experiments. They're not guinea pigs." In a proper court-ordered therapeutic program, such a mother would have no choice but to allow her child to be "experimented" with.

The therapist does well to view one aspect of the children's treatment as a kind of "debriefing" and "deprogramming." The principles used are similar to those implemented with prisoners of war who were inculcated with enemy propaganda and were brainwashed into professing public hatred of the country for which they were originally fighting. An example of this is the 
brainwashing of American prisoners of war by their North Korean captors during the Korean War. It also is similar to the kind of programming used with youngsters who were forcibly indoctrinated into religious cults that have lured children away from their families. An example of this would be youngsters who were indoctrinated into the "Moonies" cult in the 1970s. The same programming was attempted more recently for those held hostage in Iran. One must try to help PAS children appreciate that they have been brainwashed. Obviously, older children are more likely to appreciate this than younger ones. Sometimes a focus on absurd and ludicrous allegations may help the PAS child gain such insights. It also is useful to say things along these lines:

I'm not asking you to take my word for it. I want you to use your own observations. I want you to think about what happened during your last visit with your father and ask yourself whether or not the things your mother said would happen actually happened. During your next visit, I want you to keep your eyes open and come to your own conclusions regarding whether or not these dangers and practices actually exist. You say you're old enough and smart enough to come to your own conclusions. Okay, smart people come to conclusions on the basis of their own observations, not on the statements made by others-whoever they may be. lust as I asked you before to give me proof of what you believe on the basis of what you've seen in the past, I want you to give me proof next time, after your next visit, on the basis of what you yourself have actually seen and experienced.

I have come across a few situations in which the children and the family were split regarding the success of the programmer's attempts at alienation. Specifically, one or more of the children were successfully programmed, and one or more were not. I also have seen cases in which a mother was successful in programming one or more children, and the father was successful in programming one or more children. The civil war resulted in two divided camps. One maneuver (I am hesitant to call it therapeutic) the therapist might use in these situations is to formulate a "trade-off": The children in Home A will visit Home B only if the children in Home B visit Home A. Or, more specifically, if the mother wants to see the children who live in the father's home, then she must allow the children in her home to visit with the father. Such a requirement may be dictated by the court-ordered therapist and even by the court. The court order can also give the children "excuses" for visitation. I sometimes refer to this as a "trade-of-prisoners" program.

The obvious drawback of such an arrangement is that the children are truly being used as pawns in a chess game, and this cannot but be psychologically detrimental. My limited experience with such a situation has led me to the conclusion that its advantages outweigh its disadvantages. As is true with most divorce conflicts, there is no such thing as one "good" solution, one "bad" solution. Rather, we have to decide which we consider to be the least detrimental of all the detrimental options available. I consider the swapping arrangement less detrimental than no visitation at all. As mentioned, a psychological bond, no matter how strong, can tolerate only a certain degree of attenuation, beyond which it becomes destroyed completely. 
When working individually with PAS children, the therapist must discourage them from "buttering up" each parent and saying to each what they think that parent wants to hear at the moment. In family sessions the therapist should "smoke out" the lies. This is much more likely to be accomplished in family sessions than in individual meetings. Therapists should express incredulity over the children's vilification of the targeted parent. They should not take seriously the children's allegations, quickly refute and discount allegations that are patently false, and should then move on to other subjects. However after visits with the alienated parent, therapists should emphasize to the children that their view of that parent as an ogre was not realized during the visitation. The therapist does well to appreciate that as long as the litigation goes on, direct work with the children will be difficult and complete alleviation of PAS symptoms may not be possible. Accordingly, in communications to the judge, the therapist should be ever reminding him (her) of the fact that the longer the litigation goes on, the less the likelihood the treatment will be successful.

Once the court has made a final decision that the children shall remain living with the parent with whom they have the stronger, healthier psychological bond (most often the mother), then the children are often able to dispense with their PAS scenarios of deprecation. This is especially the case in the mild types of PAS and most of the children in the moderate category. This is a very important point, The children develop their campaigns of denigration because of the desire to maintain the psychological bond with the parent with whom they have been most deeply bonded. The custody litigation has threatened a disruption of this bond. Once the court has ruled that the children shall remain living primarily with the parent with whom they are more deeply bonded, they can relax and allow themselves to enjoy a more benevolent relationship with the targeted parent. In short, the court's order obviates the need for the symptoms, and so they can often be dispensed with. It would be an error for the reader to conclude that so quick an evaporation of symptoms is uniformly the case after a court order. The shorter the duration of programming, the greater the likelihood that this will happen. In contrast, if there have been many months and even years of programming, the court order is not likely to be so quickly effective. The programming has become deeply embedded in the children's brain circuitry and is not going to evaporate so quickly. Only with time, experience, and further therapy will there be any chance for the alleviation of symptoms under these circumstances.

\section{THE ALIENATED PARENT}

Parents who are the victims of PAS are often quite confused regarding what has happened to their families. The alienation may have come like "a bolt out of the blue," and they may be speculating feverishly regarding what has gone on. It is as if one day they had warm and loving children and the next day they were victims of ongoing vilification and denigration. Accordingly, after a detailed inquiry has been conducted and the diagnosis confirmed, the therapist does well to explain the process by which PAS developed. Without such an evaluation, the explanations are likely to be mere speculations. The old wisdom "knowledge is power" is applicable here. The more one understands the causes of a phenomenon, the better is one's position to deal with it.

Targeted parents must also be helped to appreciate that the opposite of love is not hate but indifference. They know quite well that prior to the onset of the campaign of denigration the 
children were friendly, loving. and reasonably cooperative. The children's sudden transformation of personality cannot possibly mean that all love and affection have been obliterated completely from their brain circuitry. The children's preoccupation with the targeted parent belies their underlying affection, as strange as this may seem to the alienated parent. I sometimes find the following example useful: Boy A meets a girl. After a few dates, he decides that he is no longer interested and does not call her. In the ensuing weeks she hardly enters his mind. In contrast, Boy B dates the same girl a few times and then writes her a 25-page letter indicating all the reasons why he no longer wants to see her again. He is preoccupied with his decision to part ways. The question is this: With which boy does the girl have a greater chance of a renewed relationship? Obviously, the answer is Boy B, even though his professions of dislike: revulsion, and even hatred would ostensibly indicate that he wants nothing more to do with the girl. His 25-page letter of rejection belies his deep ongoing involvement. The PAS child is like Boy B, and targeted parents have to continually be reminded of this.

Victimized parents also have to be helped to "thicken their skins." They must be helped not to take so seriously the children's vilifications. Many victimized parents recognize that the children are most difficult during the first minutes or hours following the transfer. Subsequently, PAS children in the mild and moderate categories tend to "relax their guard" and enjoy the visitation. Some alienated parents may have to tolerate an ongoing state of animosity throughout the course of the visit. Such parents should be encouraged, however, to continue with the visits and view the hostility as basically a mask for the programming parent's benefit. They have to appreciate that the children are indeed still visiting their protests notwithstanding. This indicates that they actually want to be with the allegedly despised parent. If they really and truly did not want to visit, as is seen in cases of children in the severe category of PAS, they would not. Even younger PAS children could create such scenes, battles, and commotion that the parents would ultimately give up in despair.

Some PAS children in the moderate category are relatively calm and happy during the first hour or two of the visit, then go through a stage of rage outbursts that last one or more hours, and then revert to their previous state of friendliness. These episodes of fury should be viewed as demonstrations for the benefit of the programmer and will be duly reported on the child's return. However, at the time of such reporting, the duration and intensity of the outbursts will predictably be expanded, exaggerated, and presented as responses to some terrible indignity suffered at the hands of the targeted parent. No mention at all will be made of the good times that might have comprised $95+\%$ of the visit. Sometimes the rage outbursts represent a release of pent-up anger generated by the child's embroilment in the parental conflict.

Victimized parents must be helped to divert the children from their hostile provocations to healthier interchanges and not to dwell on whether a particular allegation is true or false. I am not suggesting that targeted parents refrain entirely from any refutations of the false allegations; rather, they should make explanatory retorts short and simple and not devote significant time to them. They should point out to the children the most egregious examples of the programmer's distortions and ask them whether they themselves have had experiences that verify these allegations. This is best done at the time when an alleged indignity or persecution is supposed to be taking place. Healthy living experiences, however, are the most effective antidotes to the PAS child's delusions regarding the targeted parent's allegedly noxious and dangerous qualities. 
Much more time should be spent providing the children with experiences that negate the validity of the false accusations. The victimized parent can be engaged by the therapist as a therapeutic assistant in the deprogramming process. In the course of such meetings the targeted parent provides examples of the false allegations, which then serve as points of departure for a therapeutic discussion among the parties, a discussion that focuses on the falsity of the allegation.

Targeted parents should be encouraged to talk to the children about "old times" together and to engage in the playful interchanges that may have been manifestations of the bonding that took place at that time. Healthy parents and children engage in special "private" games that are unique to each relationship. These may involve singing special songs, involvement in certain playful activities, or using special terms and phrases that are ideosyncratic to that particular parent-child relationship. Engaging the children in a repetition of these activities and interchanges can be quite salutary and play an important role in reducing PAS symptoms and in rebuilding an attenuated psychological bond.

On occasion, victimized parents will request police accompaniment when they pick up their children for visitation. Typically, they bring to the visit a court order that clearly indicates to the police that the pickup time is a valid one. Obviously, this is not done the first time a separated parent visits. It is resorted to only after numerous frustrations and rejections at pickup time. As is true for most activities, there are advantages and disadvantages to this maneuver. The main advantages are that it increases the likelihood that the children will visit and thereby reduces the targeted parent's frustrations and pent-up anger. It also has an advantage for the children in that it provides them with an excuse for the programming parent; for example, "We really hate to go with him (her), but if we don't someone may get arrested." As mentioned, I cannot emphasize strongly enough the importance of providing PAS children with excuses that they need to give the programming parent if they are to visit the alienated parent. A disadvantage of bringing along the police is that it may produce fear in the children. After all, police are often seen as awesome authorities to children, and they may be frightened that they, themselves, will be arrested. I have no strong position on this particular issue. There are situations in which the advantages outweigh the disadvantages, and there are other situations in which the opposite is the case. As is true with many other clinical decisions, an empirical trial is often the best procedure for ascertaining whether a particular procedure will be beneficial. The therapist does well to explore this issue in selected cases and, when in doubt regarding what to recommend, try it once or twice and then assess the family members, especially the children, for their various reactions.

Most important, victimized parents have to be encouraged to "hang in there" with the philosophy that relationships based on genuine love may ultimately prove stronger than relationships based on fear. Alienated parents should be helped to appreciate (if they don't know already) that the children's animosity toward them is based primarily on the fear of alienating their programmers, especially if they express any affection for the alienated parent. Victimized parents should provide the children with an atmosphere in which they permit them to express all thoughts and feelings, both positive and negative, regarding both parents. This is a different environment from the indoctrinating parent's home, wherein the children are not allowed to express any criticism at all of the programmer or any affectionate feelings for the targeted parent. In the home of the 
programmer the children live in a state of fear lest they break these stringent rules. The hope is that, ultimately, the children will come to appreciate this difference and recognize the greater state of relaxation and pleasure they enjoy in the victimized parent's home.

Targeted parents in the moderate category of PAS have to be helped to appreciate that things could be worse, that the children are not in the severe category-in which situation they would not be visiting at all. The very fact that the children are visiting indicates that they want to be with the alienated parent, their protests to the contrary notwithstanding. If the children really did not want to be with the targeted parent, their ongoing screaming, kicking and blood-curdling shrieks would make visitation impossible, except for the very youngest children. Victimized parents in the moderate category have to be continually reminded of this important fact and persuaded to take some solace from this.

\section{DISCUSSION}

I can think of no better example of the way in which mental health and legal professionals can work together than the treatment of PAS families. When such cooperation is full and complete, the likelihood of success is reasonably good. In contrast, when such cooperation is not present, therapy is likely to prove futile and the result of such therapeutic failure is likely to be progression of the PAS down into the severe realm, with the high probability of lifelong alienation of the children from the targeted parent. MY experience has been that courts are generally reluctant to impose the more stringent sanctions suggested here, with tragic results for the family. My experience also has been that there are few therapists who are willing to or capable of implementing the more stringent treatment program recommended here. The "Mr. (Mrs.)-good-guy" approach, so important in traditional individual and family therapy, has no place in the treatment of PAS families. Only therapists who are comfortable with stringent and authoritarian treatment procedures should be involved in conducting therapy with PAS families. Therapists who are capable of making this switch can provide these families with significant help if they are able to gain court support for their treatment. Unfortunately, my experience has been that such support from the court is rarely forthcoming. One of my purposes in writing this article is to bring attention to this problem, in the hope that both mental health and legal professionals will modify their attitudes and thereby provide these families with sorely needed assistance, which they are not yet receiving in the vast majority of cases.

\section{REFERENCES}

Gardner, R. A. (1985). Recent trends in divorce and custody litigation. Academy Forum, 29(2), 3-7.

Gardner, R. A. (1986). Child custody litigation: A guide for parents and mental health professionals. Cresskill, NJ: Creative Therapeutics.

Gardner, R. A. (1987a). The parental alienation syndrome and the differentiation between false and genuine child sex abuse. Cresskill, NJ: Creative Therapeutics. 
Gardner, R. A. (1987b). Child custody. In J. D. Noshpitz (Ed.), Basic handbook of child psychiatry (Vol. 5, pp. 637-646). New York: Basic Books.

Gardner, R. A. (1989). Family evaluation in child custody mediation, arbitration, and litigation. Cresskill, NJ: Creative Therapeutic.

Gardner, R. A. (1991). Sex abuse hysteria: Salem witch trials revisited. Cresskill, NJ: Creative Therapeutics.

Gardner, R. A. (1992a). The parental alienation syndrome: A guide for mental health and legal professionals. Cresskill, NJ: Creative Therapeutics.

Gardner, R. A. (1992b). True and false accusations of child sex abuse. Cresskill, NJ: Creative Therapeutics.

Gardner, R. A. (1993a). The child abuse prevention and treatment act for dealing with sex abuse hysteria in the United States. Issues in Child Abuse Accusations, 5(1), 25-27.

Gardner, R. A. (1993b, February 22). Modern witch hunt-child abuse charges [Op-Ed article]. The Wall Street Journal.

Gardner, R. A. (1993c). Sex-abuse hysteria: Diagnosis, etiology, pathogenesis, and treatment. Academy Forum, 37,(3), 2-5.

Gardner, R. A. (1995). Protocols for the Sex-Abuse Evaluation. Cresskill, NJ: Creative Therapeutics.

Gardner, R. A. (1996). Psychotherapy with sex-abuse victims: True, false, and hysterical. Cresskill, NJ: Creative Therapeutics.

Gardner, R. A. (in press). The Burgess decision and the Wallerstein brief. Journal of Psychiatry and the Law, 26(3), 1-7.

Gardner, R. A. (1998). The parental alienation syndrome (2nd ed.). Cresskill, NJ: Creative Therapeutics.

Rand, D. C. (1997a). The spectrum of parental alienation syndrome (Part I). American Journal of Forensic Psychology, 15,(3), 23-52

Rand, D. C. (1997b). The spectrum of parental alienation syndrome (Part II). American Journal of Forensic Psychology, 15(4), 39-92

Waldron, K. H., \& Joanis, J. D. (1996). Understanding and collaboratively treating parental alienation syndrome. American Journal of Family Law. 10, 121-133. 